\title{
Hardware Design of Single-Phase Smart Electricity Meter based on Multiple Wireless Connectivity Technologies
}

\author{
Osman Saygın Akkaya ${ }^{1,2 *}$, Hakkı Soy $^{3}$ \\ $1^{*}$ Lamptime Electric Inc., Research and Development (R\&D) Department, Konya, Turkey, \\ 2 Necmettin Erbakan University, Institute of Science and Technology, Konya, Turkey (ORCID: 0000-0001-9491-517X), \\ oakkaya@lamptime.com.tr \\ ${ }^{3}$ Necmettin Erbakan University, Faculty of Engineering, Department of Electrical and Electronics Engineering, Konya, Turkey, (ORCID: 0000-0003-3938-0381), \\ hakkisoy@erbakan.edu.tr
}

(International Conference on Design, Research and Development (RDCONF) 2021 - 15-18 December 2021)

(DOI: $10.31590 /$ ejosat.1040829)

ATIF/REFERENCE: Akkaya, O. S. \& Soy, H. (2021). Hardware Design of Single-Phase Smart Electricity Meter based on Multiple Wireless Connectivity Technologies. European Journal of Science and Technology, (32), 332-338.

\begin{abstract}
Smart meters are an indispensable element of new generation smart grids. This study presents the hardware design of a novel singlephase smart electricity meter, which can provide energy efficiency, adaptive pricing and automated data collection functions. Besides, an extensive information is given about the Bluetooth, Wi-Fi and NB-IoT technologies that are used to transfer the electrical parameters (current, voltage, active/reactive power, power factor etc.) related with its connected load to the cloud server. Our designed smart meter has been tested by connecting to the LED lighting panel, which is supplied over the electric grid. So, the measurement validity has been verified by using the application program. Also, the smart meter readings have been successfully transferred to the mobile phone application and cloud platform with the help of available wireless connection technologies.
\end{abstract}

Keywords: Electricity, Smart Grid, Smart Meter, Bluetooth, Wi-Fi, NB-IoT.

\section{Çoklu Kablosuz Bağlantı Teknolojilerine Dayalı Tek Faz Akıllı Elektrik Sayacının Donanım Tasarımı}

$\ddot{O} \mathbf{z}$

Akıllı sayaçlar, yeni nesil akıllı şebekelerin vazgeçilmez bir unsurudur. Bu çalışmada enerji verimliliği, uyarlamalı fiyatlandırma ve otomatik veri toplama fonksiyonları sağlayabilecek özgün bir tek faz akıllı elektrik sayacının donanım tasarımı sunulmuştur. Bununla birlikte geliştirilen akıllı sayaç ile bağlı olduğu yüke ilişkin toplanan elektriksel parametrelerin (akım, gerilim, aktif/reaktif güç, güç faktörü vb.) bulut sunucusuna aktarılması için kullanılan Bluetooth, Wi-Fi ve NB-IoT teknolojileri hakkında kapsamlı bilgi verilmiştir. Tasarlanan akıllı sayaç elektrik şebekesi üzerinden beslenen LED aydınlatma paneline bağlanarak test edilmiş ve elde edilen ölçüm değerlerinin geçerli olduğu uygulama programı kullanılarak doğrulanmıştır. Ayrıca akıllı sayaç okuma değerlerinin mevcut olan kablosuz bağlantı teknolojileri yardımıyla cep telefonu uygulamasına ve bulut platformuna aktarımı başarıyla gerçekleştirilmiştir.

Anahtar Kelimeler: Elektrik, Akıllı Şebeke, Akıllı Sayaç, Bluetooth, Wi-Fi, NB-IoT.

* Corresponding Author: oakkaya@lamptime.com.tr 


\section{Introduction}

Electricity has a great importance on the sustainable development of modern societies. Today, it is not possible to live a comfortable life without electric energy. Most if not all domestic and industrial applications (e.g., lighting, heating, ventilation and air conditioning, communication, transportation) mainly depend on electricity (AGECC, 2010). During the last decades, due to the massive increase in energy demand in parallel with global population growth, it has become a necessity to develop optimization strategies to ensure a balance between the electricity generation and consumption. According to this motivation, an urgent need has arisen for smart technologies that will improve the efficiency in electric grids (EAC, 2008). Nowadays, the innovative concepts of 'smart grid' and 'smart meter' have been emerged in response to rising expectations of regulatory authorities and energy retailers (Amin et al., 2013; USDE, 2018).

A smart grid can be defined as an advanced electricity delivery system, which intelligently manages the operations, planning and maintenance activities to optimize the energy use and costs. The main purpose is to make guarantee that electricity is always provided without interruption. It also gives effectiveness to the utility companies to control the operating costs, improve the reliability and deliver the well-functioning services to consumers (Momoh, 2012). The end user's energy demand varies according to prominent factors affecting the consumption. Especially, the weather has significant effect on peak energy demand as a noncontrollable factor. The peak demands due to extreme weather conditions (i.e., air conditioning in summer days, electric heating in winter months) cause the disturbances in the electric grids. In order to ensure a stable and reliable grid operation, the electricity service providers have to forecasts the quantity and quality of delivered electricity to customers (EMRA, 2018).

It is clear that a typical electricity supply chain consists of generation, transmission, distribution and retail stages between the power plant and customers. Smart grids combine the communication technologies and metering solutions with conventional energy distribution network to improve the performance of electricity supply chain (Gungor, et al., 2011; Escobar et al., 2021). The real-time implementation of smart grid applications heavily depends on advanced metering infrastructure (AMI) that ensures remote interaction between the electric utility company and the consumer through smart meters. The AMI is a complete energy network that enables automated metering with the help of the communication between a smart meter and utility company. It mainly consists of smart meters (hardware), communication network as well as data management system (software) to measure, collect, record and analyze the load profiles of customers (Alotaibi et al., 2020; Martins et al., 2019).

The smart metering is an indispensable part of smart grids that allow lower cost, energy saving as well as working with dynamic tariffs and variable pricing. A smart electricity meter is a device that can able to record the energy consumption continuously and send the detailed information for billing to the electricity provider (Atiç et al., 2015). Different from ordinary electromechanical meters, the smart meters can measure the power demand of the consumers and power quality of entire grid. Beyond that, a typical smart meter receives the control information from provider. Thanks to bi-directional preventive information flow, the electric utilities can manage the load, protect the distribution network and improve the operational efficiency.
Also, the consumers can make better energy saving decisions to reduce the monthly bill (Barai et al., 2015; Misra and Bera, 2018).

There is no doubt that the advances in technology are forcing many advanced countries to reconsider their way of electrical energy production and consumption. Grid modernization is an absolutely essential vision to protect the power infrastructure from damage due to excessive demand. Looking from this perspective, the smart meter applications are the major triggers for a speeding up of the digitalization in electric grids (Wang et al., 2018; Ma et al., 2021). In this study, we have presented design and implementation of a novel smart electricity meter for real time monitoring of single-phase electrical energy measurements. Our designed smart meter has ability to collect the electrical data such as current (A), voltage (V), active power $(\mathrm{P})$, apparent power $(\mathrm{S})$, power factor $(\mathrm{PF})$, reactive power $(\mathrm{Q})$, line frequency $(\mathrm{LF})$ and also send them to remote monitoring center via one of the available wireless communication technologies.

The remainder of paper is organized as follows: Section 2 describes the hardware design of our smart electricity meter prototype. Section 3 explains the communication capabilities of smart meter to send the readings to get accurate bills. The test implementation procedure is discussed in Section 4. Finally, Section 5 concludes the study by giving some recommendations for future research.

\section{Hardware Design}

The designed smart electricity meter equipped with STM32F407VGT6 microcontroller, MCP39F511 single-phase power-monitoring chip, BC95-G NB-IoT module and ESP32WROOM-32 module. Figure 1 shows the basic hardware building blocks of our smart electricity meter design. STM32F407VGT6 microcontroller is manufactured by STMicroelectronics and it has 32-bit ARM Cortex-M4 with FPU core with $168 \mathrm{MHz}$ frequency (STMicroelectronics, 2020). Microchip MCP39F511 is used for real-time measurement of input power for AC/DC power supplies, power distribution units, consumer electronics and industrial applications. It includes dual-channel 24-bit Delta-Sigma ADCs for current and voltage inputs. Analog signals are converted to digital at the ADCs, which consist of an interpreter, a single bit digital to analog conversion (DAC) and a latched comparator (Microchip, 2015). Then, the microcontroller calculates the power usage by measuring the instant voltage and current values.

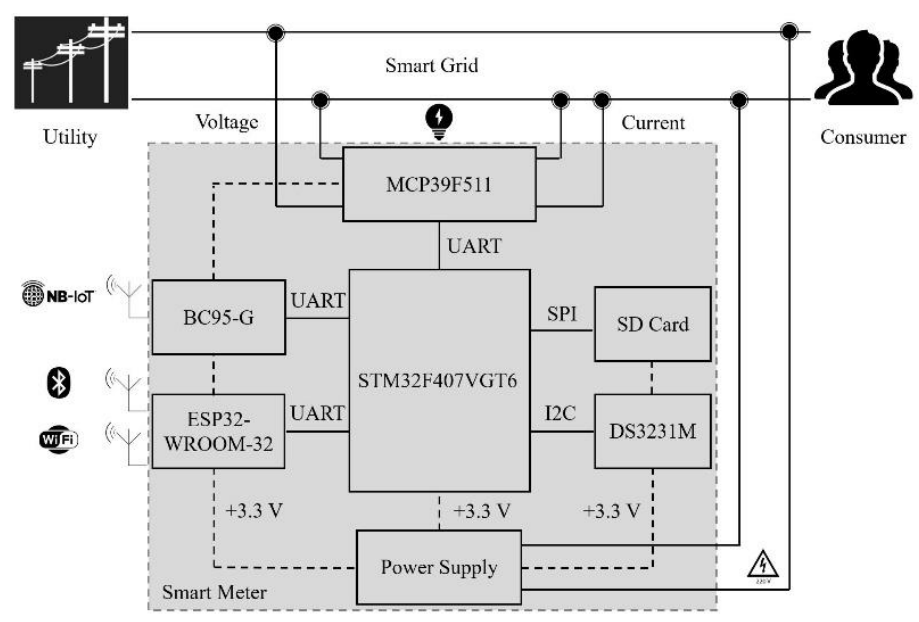

Figure 1. Hardware building blocks of smart meter design 
Designed smart meter has integrated with two different RF modules to establish a wireless communication link to application server. Quectel BC95-G is a high-performance NB-IoT module. It communicates with the microcontroller via UART interface and supports multiple frequency bands (B1:2100 MHz / B3:1800 $\mathrm{MHz} / \mathrm{B} 5: 850 \mathrm{MHz} / \mathrm{B} 8: 900 \mathrm{MHz} / \mathrm{B} 20: 800 \mathrm{MHz} / \mathrm{B} 28: 700$ $\mathrm{MHz}$ ). The maximum output power and receiver sensitivity are is $+23 \mathrm{dBm}$ and $-129 \mathrm{dBm}$, respectively. BC95-G module operates between 3.1 to 4.2 volts. Its compact form makes it convenient for smart metering applications (Quectel, 2020). Besides, Espressif Systems' ESP32-WROOM-32 is a powerful microcontroller module, which offers Wi-Fi and dual-mode Bluetooth connectivity options. It is compliant with IEEE $802.11 \mathrm{~b} / \mathrm{g} / \mathrm{n}$ standards as well as Bluetooth v4.2 BR/EDR and Bluetooth Low Energy (BLE) specifications (Espressif, 2021).

Designed smart electricity meter is also equipped with DS3231M real-time clock (RTC) chip and SD card reader to record the readings with timestamp. Maxim Integrated DS3231M is a low-cost and extremely accurate RTC chip. It is connected to the microcontroller using I2C interface. The cell type battery is used as a backup to keep time/date information in case of main power failure (Maxim, 2015). When the communication is lost from smart meter to utility center, the collected meter readings are saved to SD card. It has to be highlighted that the designed smart meter is powered by line voltage. So, in order to meet the strict voltage and current requirements of different hardware blocks, we have designed a power supply circuitry (step-down transformers, $\mathrm{AC}-\mathrm{DC}$ and DC-DC converters, rectifiers and regulators) by converting AC line voltage to a lower DC voltage level. Figure 2 shows the complete schematic of our designed smart meter.

Finally, we have realized our designed smart electricity meter as a light and compact electronic device. When the printed circuit board (PCB) layout has been created from schematic diagrams of simulated circuits, we have separated the power monitoring block from computing and communication blocks to mitigate the unwanted effects. To put it more clearly, we have carried the microcontroller, RF transceiver modules and other components to main board, while the power monitoring circuitry has been placed on the daughter board. These two boards have been connected to each other using a header connector. So, we have assembled the integrated boards into a case, as shown by Figure 3.

\section{Communication Technologies}

Smart meters need a reliable communication network and there are several wired and wireless connectivity options available that can be used to access the utility center (Zheng et al., 2013; Pauzet, 2010). Choosing the right communication technology is a major challenge faced by many grid operators that want to progress. The optimal connectivity option should be lower installation cost, easy to operate and contain a highly integrated network (Kabalci, 2016; Seelmann et al., 2018). This section explains the connectivity options of our designed smart electricity meter. As mentioned before, we have used the Wi-Fi, Bluetooth and NB-IoT technologies to exchange data between the smart meter and remote server. Indeed, all these connectivity options should not be regarded as rivals or alternatives to each other, but instead they can be seen as complementing each other. When considered the connection properties of preferred communication technologies, it can be seen that we have introduced suitable solutions for different application scenarios.
NB-IoT (also known as LTE Cat NB1) is one of the most suitable technologies for smart metering. It has been introduced by 3GPP in Release 13 to enable low-power wide-area network (LPWAN) infrastructure through the existing infrastructure of mobile operators. Thanks to using the existing LTE infrastructure (base stations, core network) and licensed spectrum, NB-IoT has an advantage of reduced interference, high capacity and reliable data transmission (Mekki et al., 2019). NB-IoT connections can be deployed in three modes specified by 3GPP. LTE 'in-band' deployment utilizes the resource blocks within a normal LTE carrier. LTE 'guard-band' deployment utilizes the unused resource blocks within the LTE carrier's guard-band. LTE 'standalone' deployment utilizes the dedicated spectrum, which is not used by any other services. In Europe, the spectrum allocated for the standalone deployment is the $700-800 \mathrm{MHz}$ band (Mwakwata, et al., 2019). Fundamentally, NB-IoT provides a wireless wide area network (WWAN) that establishes communication infrastructure over the large geographical area. This extended coverage allows to directly transfer the smart meter readings to the remote server, even if it is far away (Santoso et al., 2019)

Wi-Fi is a family of wireless network protocols and refers to all major revisions of IEEE 802.11 standards: a, b, g, n, ac, ax. The primary design objective is providing a broadband Internet access for laptops and mobile phones. Wi-Fi is the fastest of all the wireless technologies and every revision of IEEE 802.11 standard has been increased the data transmission rate on the channel. The commonly used IEEE 802.11 n operates on both the $2.4 \mathrm{GHz}$ and the $5 \mathrm{GHz}$ bands. It increases the data rate up to 150 Mbps with the help of multiple antennas. The maximum outdoor coverage range is about 250 meters (Chen, 2017; Karmakar et al., 2017). The latest IEEE 802.11ax, also known as Wi-Fi 6, offers theoretical speeds of up to $10 \mathrm{Gbps}$. Also, it significantly increases the coverage range (Cisco, 2020). Basically, Wi-Fi connectivity provides a wireless local area network (WLAN) that connects the devices inside a building. In case of a building with a Wi-Fi access point inside or around it, the smart meter readings can be transferred to the utility center by this way. It is very convenient to use Wi-Fi connectivity for smart meters working in residences, commercial offices and industrial facilities (Hlaing, et al., 2017).

Bluetooth is a wireless technology that is primarily designed for device-to-device communication of mobile equipment such as smart phone, tablet and laptop. It is built on top of the IEEE 802.15.1 standard. It offers a low cost, short range and low power connectivity via a wireless link at $2.4 \mathrm{GHz}$ ISM band. The Classic version of Bluetooth (1.0-3.0) has significantly lower data rate, limited coverage and also supports less number of devices. Bluetooth Classic compatible devices consume large amount of power in operation (Oliveira et al., 2019). In order to improve the power efficiency of battery-powered devices, the BLE was introduced in the 4.0 version of the Bluetooth (Tosi et al., 2017). Principally, Bluetooth connectivity establishes a wireless personal area network (WPAN) that allows the transmission of voice and data between the devices in close proximity to one another. It is noteworthy that our smart meter design has not been included a display to inform the consumers. Instead of that, we have considered to send the actual meter readings to the consumer's mobile devices via Bluetooth link and displaying them in the mobile application. Beyond that, if required, it is possible to send the meter reading and control messages to utility center via mobile devices. Figure 4 shows all these connectivity options of our designed smart electricity meter. 

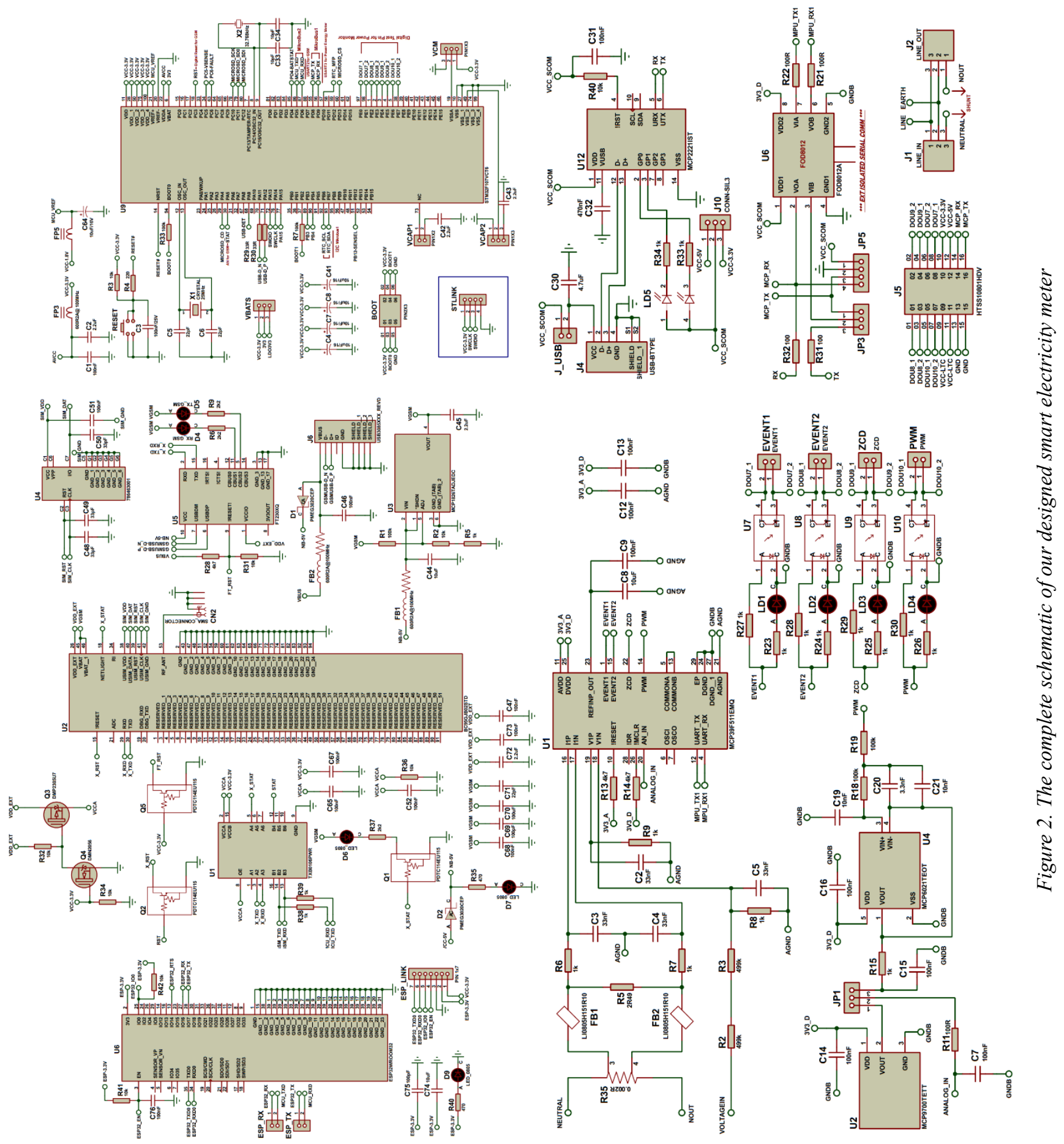

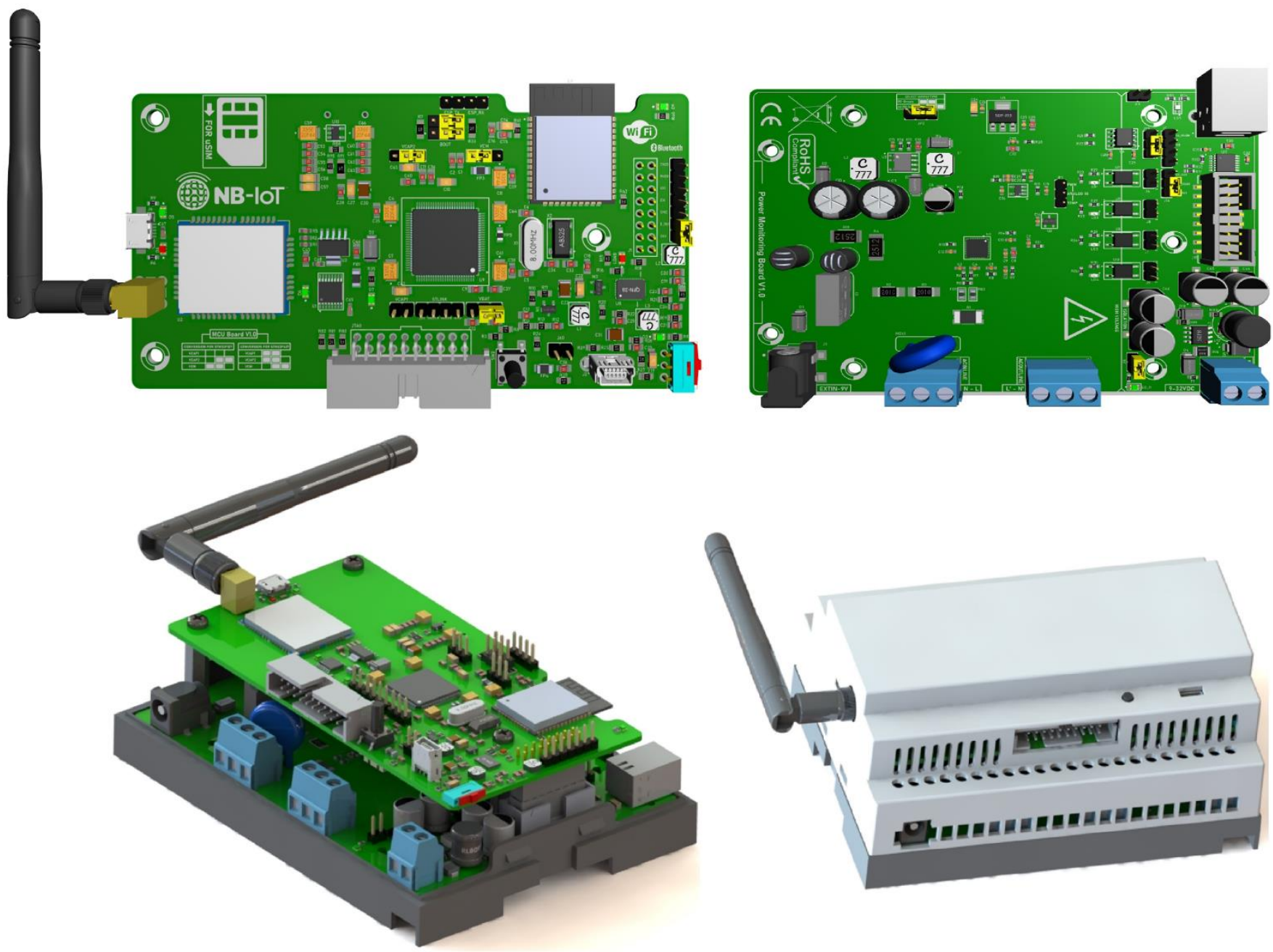

Figure 3. The prototype design of single-phase smart electricity meter

\section{Test Implementation}

After the hardware design, firmware development and prototyping, we have tested the designed smart electricity meter to validate the measured electrical parameters. A typical smart electricity meter can be connected with various equipment and instruments in industrial, commercial or residential building. The test implementation of our smart meter has been done by connecting a LED lighting panel. At this point, it should be emphasized that the power quality is extremely important for LED lighting power supply to guarantee the reliable operation and increase the life time. The poor power quality results in high costs due to the failures and malfunctions. Power quality can be defined as a grid's stability to supply a robust electrical power to load. The major causers are long duration variations (sags and swells), fluctuations and unbalance in voltage, transient over voltages as well as harmonics. As shown by Figure 5, all the smart meter readings were collected on a computer via USB port and monitored by using Microchip Power Monitor software. Then, we have compared them with measurement of test devices. The obtained results have confirmed that designed smart electricity meter has been successfully done power monitoring.

On the other side, we have also tested the remote data transfer process from smart meter to cloud server. For this purpose, we have created a mobile application using Blynk application and also a cloud platform with ThingSpeak application. The cloud computing is a current trend for Internet services due to its advantages such as low cost, flexibility and scalability in many applications. It introduces a new way to remotely store and access data rather than hosting it on local servers or hard drive of personal computers. Designed smart meter has ability to access a cloud-based application through an access point or base station.

\section{Conclusion}

Nowadays, many countries actively looking to adopt the smart grid technology to overcome the potential problems of conventional electric grids. Smart meters are the key enablers of smart grids and they help the consumers to control their individual energy usage levels. Also, thanks to smart metering, the electricity suppliers can easily monitor the grid in real time for potential disturbances, offer adaptive pricing models and achieve a more accurate demand response. This study presents the hardware design of smart electricity meter and explains its communication capabilities to transfer the consumed energy to energy supplier. By depending on the application requirements, designed smart meter can use one of its available communication technologies to transmit data to the utility center. In our future studies, we will investigate the data analytics and machine learning techniques to analyze the load profiles of consumers. We hope that our designed smart electricity meter will be an excellent test bed to develop the new algorithms and novel methods, which can improve the efficiency of conventional grids. 


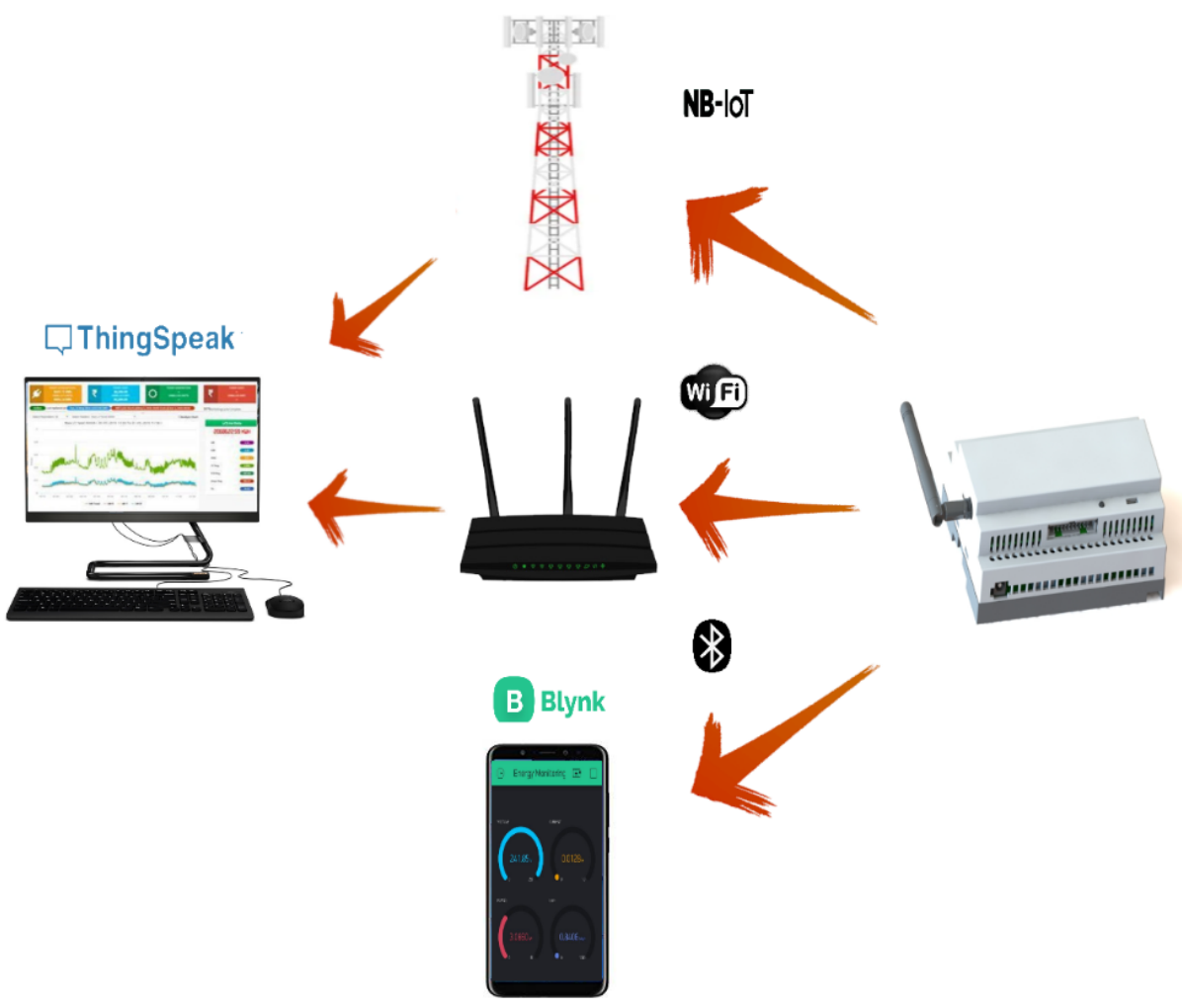

Figure 4. The connectivity options of designed smart meter for remote server access
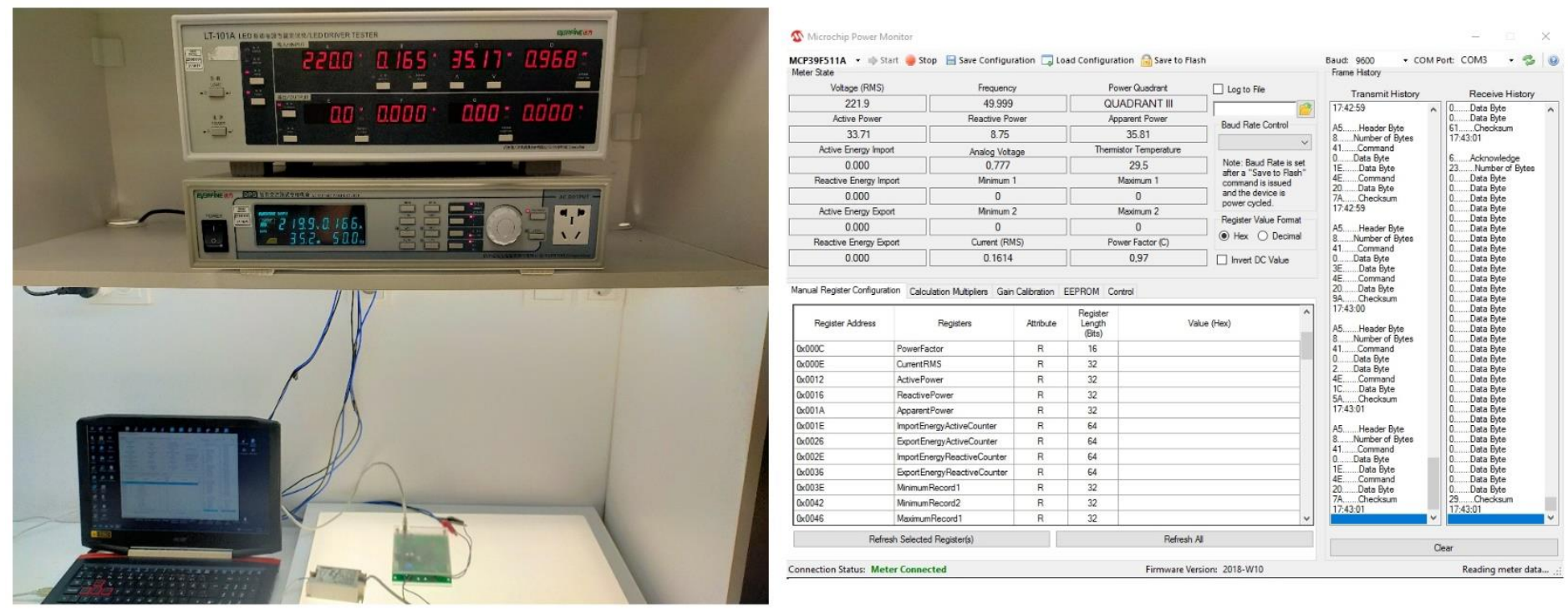

Figure 5. The test setup for the validation of smart meter readings 


\section{References}

AGECC. (2010). Energy for a Sustainable Future. United Nations.

Alotaibi, I., Abido, M. A., Khalid, M., and Savkin, A. V. (2020). A Comprehensive Review of Recent Advances in Smart Grids: A Sustainable Future with Renewable Energy Resources. Energies, 13(23), 1-41.

Amin, M., Annaswamy, A. M., DeMarco, C. L., and Samad, T. (2013). IEEE Vision for Smart Grid Controls: 2030 and Beyond.

Atiç, S., Parlakyıldız, Ş., and İlcihan, Z. (2015). Smart Meter and Turkey. Bitlis Eren University Journal of Science and Technology, 5(2), 92-96.

Barai, G. R., Krishnan, S., and Venkatesh, B. (2015). Smart Metering and Functionalities of Smart Meters in Smart Grid: A Review. IEEE Electrical Power and Energy Conference (EPEC), (pp. 138-145). London, ON, Canada.

Chen, D. (2017). A Survey of IEEE 802.11 Protocols: Comparison and Prospective. Advances in Engineering Research, 141, $569-578$.

Cisco. (2020). IEEE 802.11ax: The Sixth Generation of Wi-Fi.

EAC. (2008). Smart Grid: Enabler of the New Energy Economy. Electricity Advisory Committee.

EMRA. (2018). The Turkey Smart Grids 2023 Vision and Strategy Roadmap Project (TAS 2023). Energy Market Regulatory Authority (EMRA) and Association of Distribution System Operators (ELDER).

Escobar, J. J., Matamoros, O. M., Padilla, R. T., Reyes, I. L., and Espinosa, H. Q. (2021). A Comprehensive Review on Smart Grids: Challenges and Opportunities. Sensors, 21, 1-41.

Espressif. (2021). ESP32- WROOM-32 Data Sheet (Version 3.2).

Gungor, V. C., Sahin, D., Kocak, T., Ergut, S., Buccella, C., Cecati, C., and Hancke, G. P. (2011). Smart Grid Technologies: Communication Technologies and Standards. IEEE Transactions on Industrial Informatics, 7(4), 529-539.

Hlaing, W., Thepphaeng, S., Nontaboot, V., Tangsunantham, N., Sangsuwan, T., and Pira, C. (2017). Implementation of WiFibased single phase smart meter for Internet of Things (IoT). International Electrical Engineering Congress (iEECON), (pp. 1-4).

Kabalci, Y. (2016). A survey on smart metering and smart grid communication. Renewable and Sustainable Energy Reviews, 57, 302-318.

Karmakar, R., Chattopadhyay, S., and Chakraborty, S. (2017). Impact of IEEE 802.11n/ac PHY/MAC High Throughput Enhancements on Transport and Application Protocols-A Survey. IEEE Communications Surveys \& Tutorials, 19(4), 2050-2091.

Ma, Z., Clausen, A., Lin, Y., and Jørgensen, B. N. (2021). An overview of digitalization for the building-to-grid ecosystem. Energy Informatics, 4(36), 1-21.

Martins, J. F., Pronto, A. G., Delgado-Gomes, V., and Sanduleac, M. (2019). Smart Meters and Advanced Metering Infrastructure. In A. Taşcıkaraoğlu, \& O. Erdinç, Pathways to a Smarter Power System (pp. 89-114).

Maxim. (2015). DS3231M Real-Time Clock Data Sheet (Rev 7).

Mekki, K., Bajic, E., Chaxel, F., and Meyer, F. (2019). A comparative study of LPWAN technologies for large-scale IoT deployment. ICT Express, 5(1), 1-7.

Microchip. (2015). MCP39F511 Power-Monitoring IC with Calculation and Energy Accumulation.
Misra, S., \& Bera, S. (2018). Smart Grid Technology: A Cloud Computing and Data Management Approach. Cambridge.

Momoh, J. (2012). Smart Grid: Fundamentals of Design and Analysis. New Jersey: John Wiley \& Sons.

Mwakwata, C. B., Malik, H., Alam, M. M., Moullec, Y. L., Parand, S., and Mumtaz, S. (2019). Narrowband Internet of Things (NB-IoT): From Physical (PHY) and Media Access Control (MAC) Layers Perspectives. Sensors, 19(11), 1-34.

Oliveira, L., Rodrigues, J. J., Kozlov, S. A., Rabêlo, R. A., and Albuquerque, V. H. (2019). MAC Layer Protocols for Internet of Things: A Survey. Future Internet, 11(1), 1-42.

Pauzet, O. (2010). Cellular Communications and the Future of Smart Metering. Sierra Wireless.

Quectel. (2020). BC95-G Multi-band NB-IoT Module with Ultralow Power Consumption (Rev. V1.9).

Santoso, E. S., Hidayati, A., Suryanegara, M., and Nashiruddin, M. I. (2019). NB-IoT Network Planning for Smart Metering Services in Jakarta, Depok, Tangerang, and Bekasi. 16th International Conference on Quality in Research (QIR): International Symposium on Electrical and Computer Engineering, (pp. 1-6). Padang, Indonesia.

Seelmann, V., Nienke, S., Schwank, M., and Schölling, M. (2018). Selecting Communication Technology Components for the Smart Grid: A Technology Configurator. Journal of Communications, 13(10), 581-587.

STMicroelectronics. (2020). STM32F405xx STM32F407xx Data Sheet (DS8626 Rev 9).

Tosi, J., Taffoni, F., Santacatterina, M., Sannino, R., and Formica, D. (2017). Performance Evaluation of Bluetooth Low Energy: A Systematic Review. Sensors, 17(12), 1-34.

USDE. (2018). Smart Grid System Report. United States Department of Energy.

Wang, Y., Chen, Q., Hong, T., and Kang, C. (2018). Review of Smart Meter Data Analytics: Applications, Methodologies, and Challenges. IEEE Transactions on Smart Grid, 10(3), 3125-3148.

Zheng, J., Gao, D. W., and Lin, L. (2013). Smart Meters in Smart Grid: An Overview. IEEE Green Technologies Conference, (pp. 57-64). Denver, USA. 